\title{
Integration of Capacity Markets into the European Electricity Market
}

\author{
Giorgos Stamtsis ${ }^{1}$, Vassilis Lychnaras ${ }^{2}$
}

\begin{abstract}
The present paper analyses the evolution of the capacity markets within the context of the European electricity markets. Specifically, it analyses the history of European capacity markets and the new challenges that the emergence of these markets brings to the process of the European internal market.
\end{abstract}

\section{Introduction-Why capacity markets?}

Traditionally, electricity suppliers charge their customers, in the most cases, through a bionomial function. One part is related to the consumed electric energy while the other part refers to the (usually maximum) power recorded (or contracted) at consumer's metering point during a certain period. At the beginning of the liberalization era in the electricity markets, it was proposed that energy-only markets would be sufficient to attract the necessary investments because, through the marginal pricing of the energy, medium and peak load generators would cover their fixed costs by receiving higher-than-variable-cost revenues from the market at times of scarcity [1]. Indeed, energy-only market have been the main market design in the first years of the market liberalization and remains so in many regions worldwide. However, the original assumption about the sufficiency of the energy-only markets has been

\footnotetext{
${ }^{1}$ Hellenic Association of Independent Power Producers, Kifissias 124 \&Iatridou 2, 11526 Athens, Greece (e-mail: g.stamtsis@haipp.gr)

${ }^{2}$ Centre for Planning and Economic Research (KEPE), Amerikis 11, 10672 Athens, Greece (e-mail: vlychn@kepe.gr)
}

confronted with real market conditions in most of the cases. There is a number of reasons why selling just energy (in forward, day-ahead, intraday and balancing markets) could not cover the full cost of generators in many different markets worldwide. The most important reasons are:

a. Politicians and regulators are usually reluctant towards having (very high) spikes in the wholesale market prices, which on the other hand are necessary so as for the generators to cover fixed cost (above the variable cost that they cover when the marginal price equals their variable cost). So, barriers (like price caps) are established so as to ensure that prices will be limited.

b. In times of scarcity, Transmission System Operators (TSOs) prefer to procure energy through non-pricing actions (separated bilateral contracts, rolling blackouts, etc). Thus, wholesale market prices do not increase high enough [2].

c. Most of the customers are non-price sensitive and are not equipped with real time metering devices so as to react at price spikes.

d. Due to the high penetration of intermittent RES with almost zero variable cost and dispatch priority

i. The operational hours of conventional units have been drastically limited.

ii. Wholesale market prices are kept at low levels

The result of all these reasons is that the conventional units, especially the medium and peak load units, are not able to fully cover their cost by participating in an energyonly market. On the other hand, conventional dispatchable units are needed in order to cover the yearly (and seasonal) peak demand (during dozens or few hundred hours) but also on daily basis (the flexible

This is an Open Access article distributed in accordance with the Creative Commons Attribution Non Commercial (CC-BY-NC-ND 4.0) license, which permits others to copy or share the article, provided original work is properly cited and that this is not done for commercial purposes. Users may not remix, transform, or build upon the material and may not distribute the modified material (http://creativecommons.org/licenses/by-nc/4.0/) 
dispatchable units) so as to cover the variable generation of RES and provide the necessary ramping flexibility to the system.

Thus, capacity markets provide an additional revenue stream to the conventional units along with the revenues they can ensure through the energy and ancillary service markets.

\section{Institutional developments}

As the next section illustrates, capacity markets do exist in the European continent for a while. But it is the last couple of years that the discussion about capacity markets has taken a more institutional character.

First of all, the European Commission has for the first time included the capacity markets in the latest Guidelines on state aid for environment and energy [3]. By doing so, EC intends to set a European-wide framework for the implementation of capacity markets so as this market design change will not hinder the path towards the internal energy market. In the text of the Guidelines, EC defines that cross-border participation in any capacity market is the most crucial factor regarding the compatibility of capacity markets with the aim of the internal energy market. The Guidelines also pay attention to the flexible generation capacity which is needed to cover the renewables' intermittency. Additionally, the Guidelines provide clauses that aim not to prevent the phasing out of environmentally harmful subsidies. EC's worry is that realization of capacity markets could keep online for longer time high-CO2 emitting units and thus undermine the ambitious EU's decarbonisation goals.

The European energy regulator ACER [4] includes in its proposal towards 2025 that the Agency along with the national regulators will monitor the generation adequacy issue and the impact of capacity markets on the internal energy market. For ACER, as well as actually for the EC as a whole, the increasing trend of member-states adopting some kind of capacity markets does not change the view that energy-only market is the preferable market design and that capacity markets should be implemented if changes in energy-only market design cannot deliver the necessary generation adequacy.

From its point of view, the European network of the TSOs [5], proposes that market participants should be given the incentive to support the system adequacy by taking a risk of that (e.g. price volatility, capacity shortage). ENTSO-E draws the conclusion that once the market participants bear that risk then they will seek to hedge it through different products, among them also through capacity markets. ENTSO-E elaborates further this proposal [6] in order to safeguard that the emerging capacity markets will be open to cross-border participation and in-line with the ultimate goal of the internal energy market.

Eurelectric, as the association of the European electricity companies, has developed a concrete proposal regarding the implementation of the capacity markets [7] where the capacity markets become an integral part of the future market design. Again, the most crucial point is the cross-border participation that will make this design to be in line with the internal energy market.

On intergovernmental level, the most interesting development is the initiative [8] of twelve neighbouring countries (Belgium, the Netherlands, Luxembourg, France, Germany, Austria, Switzerland, Norway, Sweden, Denmark, Poland, and the Czech Republic,) to sign a declaration in June 2015 to start considering security of supply in electricity as a European issue instead of a national one. According to that declaration, the twelve countries will refrain from introducing legal price caps and eliminate barriers to greater flexibility. Doing so, they will try to solve the missing money problem through energy-only market (with high price spikes) and the generation adequacy problem through regional cooperation. Of course, it has to be underlined that some of these countries (e.g. France) have already implemented capacity market.

\section{Capacity markets in EU countries}

This section presents a synopsis of the different capacity mechanisms that have already been implemented or are planned to be so in European countries.

\subsection{Greece}

The Greek electricity market regulatory framework has adopted a capacity obligation scheme since 2005 . According to that scheme, suppliers representing consumers (or exports) are obliged to submit to TSO available capacity certificates depending on the consumption profile of their clients during system's stressed hours. Such certificates are issued by dispatchable generation units proportionally to their actual available capacity. The scheme is actual a decentralized bilateral trading of capacity certificates between suppliers and generators [9]. However, due to the high concentration in the Greek retail market (the incumbent still has a $97 \%$ market share in retail) this scheme would practically not work and that is why it has been replaced by a transitional capacity payment scheme. This payment scheme was market-wide and was implemented from 
2005 to 2014. The certificate price charged to suppliers varied from 35.000 Euro/MW-year to 56.000 Euro/MWyear during that period.

Nowadays, the Regulator has proposed, in cooperation with DG Comp, a new direction for the capacity market, i.e. remuneration of flexible dispatchable units instead of market-wide payments. The new direction would be implemented in a two-phase process. The first one would last just 10 months (during 2015) and foreseeing fixed payments to gas-fired and hydro units (the flexible dispatchable units) of 45.000 Euro/MW-year. Total remuneration to generators would cumulate, according to this scheme, to ca. 220 million Euro on yearly basis. That is a $61 \%$ reduction in comparison to the previous capacity scheme. From November 2015 onwards a new capacity market would emerge with the TSO conducting yearly auctions for the procurement of the necessary flexible generation capacity (i.e. a central auction system). However, up to date neither the short first-phase has been implemented nor any step towards the design and implementation of the second phase has been announced. Because a) the incumbent has practically still exclusive access to lignite and hydro sources and this fact induces a very limited competition in generation and hence in retail market and b) the design of the Greek electricity market has remained uncompleted (there is only day-ahead marker and not forward, intraday and balancing markets), generators (especially the medium and peak load ones) have limited opportunity to collect the necessary revenues from the energy market and thus they seek higher revenues from the capacity market. It is expected that the implementation of Regulator's roadmap towards a market compatible with the provisions of the target model will result in better disclosing of electricity's real value at any time horizon and thus it will lower the revenues the generators aim at through the capacity market.

\subsection{France}

The promotion of hydro-power, nuclear power and RES in France, helped the country's electricity market become independent and competitive, as well as reduce carbon emission. On the other hand, the market is characterised by intense peak demand phenomena. In 2010, the French electricity market has been reformed (NOME) and the reformed market called for the creation of a capacity obligation scheme. The general framework for the new scheme has been defined in December 2012. The proposed mechanism will be regulated by public authorities and intends to provide a form of "insurance" for the periods of tight supply and the generators will be rewarded to be available during the above periods.

The French capacity mechanism was designed to address this issue by modifying consumption behaviour during peak periods (demand-based approach) while encouraging adequate investment in generation and demand response capacities. The purpose was to create a mechanism that allows market stakeholders to trade capacity certificates so that security of supply target can be met at the least possible cost. The mechanism will allow consumers and suppliers to manage the risk represented by capacity obligations by leveraging their demand response potential during peak periods. Obligations will be assigned to suppliers based on the actual consumption of their customers during peak periods. To meet its obligation, a supplier will have to secure capacity certificates, either by certifying the capacities it operates (generation or demand-side capacities) or by purchasing certificates from players that hold them [10].

The individual obligations will be defined based on parameters established four years before the target delivery year and will be updated. In accordance with the terms of the decree, the first delivery year, will begin on 1 November 2016 and end on 31 December 2017, excluding July and August 2017.

\subsection{Belgium}

The Belgian electricity market is facing more and more important structural changes, such as the integration of RES and the scheduled decline of nuclear production. More specifically, the integration of intermittent renewable capacity will stress the current energy production, as more flexible capacity needs to be dispatchable in order to cope with congestions. Additionally, Belgian government decided in 2003 to definitely step out of nuclear generation in 2025 [11]. Currently, nuclear energy represents more than $50 \%$ of the total generated electricity and more than a third of the total installed capacity [12].

Another important characteristic of the Belgian electricity market is that $30 \%$ of the installed capacity is Combined Cycle Gas Turbine (CCGT) and gas turbine. On the other hand, the increasing share of renewable has a big impact on the operating hours and profitability of necessary flexible gas fired power plants. As a consequence, the need to generate a larger share of electricity from renewables, will ask for more flexibility in terms of production and/or demand, but the most flexible power plants, namely gas fired power, are pushed out by renewables [11]. 
The Belgian electricity system is in a transition period, facing adequacy and flexibility issues. In June 2012, Plan Wathelet proposed three mechanisms to ensure security of supply at reasonable cost and with respect to the transition to a new energy model: (a) A better framework for definitive and temporary closures of production units. A new legislation is proposed, making possible that a specific production unit stays available in a strategic reserve, only to be used when the security of supply is threatened, (b) A better planning for the nuclear phaseout, including the provision of the extended part of the nuclear capacity on the market and (c) Triggering the procurement procedures foreseen in Belgian and European legislations to install new production capacity. The government will make it possible to get an assured profitability of the new installed capacity [11]. In July 2013 the Belgian Government approved the Plan Wathelet. The series of measures to mitigate Security of Supply (SoS) risks, include: (a) Interconnections, (b) Demand response and (c) Capacity that focuses in: (i) State tendering for new capacities and (ii) Creation of strategic reserve [12].

\subsection{Italy}

The Italian market strongly depends on imports and has frequent balancing problems, while, a further shift to renewables will increase the problem. Following the black-out of June 2003, in April 2004 a temporary capacity payment scheme was implemented. The mechanism provided compensation to producers who make back-up generation capacity available during critical days [9] (EC, 2013a).In Italy, like in most other EU Member States, the impact of the economic crisis and the resulting reduction of demand for electricity, combined with the growth of both conventional and renewable capacities, have led to the current situation of overcapacity and low wholesale market prices [13]. Nevertheless, the prices of the above mechanism seem insufficient to incentivize new investments and for this reason a detailed proposal for a new CRM system was published in February 2013 [14].The initial plan involved a four-year planning horizon, in line with other European capacity mechanisms such as the UK's, the idea being to increase participation from new entrants, stimulating competition between existing producers and newcomers [15].

Today, Italy is heading towards the full implementation of a capacity payment model. The Italian capacity payment model was prepared by the Italian grid operator, Terna S.p.A (Terna) and was approved, on 30
June 2014, by the Italian Ministry of Economic Development with the endorsement of the Italian Regulatory Authority for Electricity Gas and Water (AEGW). The intent is to ensure a system that has the availability of electricity capacity over the long term, so as to be able to react promptly in case of changes in consumption, to manage any security issues and ultimately to ensure that final customers are not affected by any risk-pricing. Italy has opted for an auction mechanism ensure capacity, and initially set a date for the first of such auctions in 2017. Terna, however, recently proposed to the Ministry of Economic Development the first auction be held earlier, i.e. by the end of September 2015, so that it could start producing its effects in2017[13].

The level of capacity to be made available will be determined on the basis of the expected consumption and reserve requirements, taking into account the effects of energy efficiency measures and renewable energy production. Terna will manage specific supply auctions where power producers can sell option contracts, covering the estimated amount of back-up capacity needed for that year. Consequently, power producers will have to guarantee a certain availability capacity, in the options contracts, so that Terna can call on these plants if necessary [13]. The system will include three different types of auctions:

i. Main Auction, where Terna will sign contracts with power producers for long-term supply. Auction will be performed on a yearly basis and the planning time horizon will be 4 years, while the delivery period will be 3 years.

ii. Complementary Auction to provide additional capacity on the basis of the main auction's mechanism. The planning time horizon will be 4 years and the delivery period will be 1 and 2 years.

iii. Adjustment Auction to modify the long-term positions whenever market conditions change after the long-term deals. Auctions will be performed on a yearly basis and the planning time horizon will be up to 3 years, while the delivery period will be 1 year.

\subsection{Spain}

The share of renewables in Spain increased rapidly during the last years (e.g. from $20 \%$ in 2006 to $32 \%$ in 2011). On the other hand, the annual demand for electricity was almost stable for the period 2006-2011. Additionally, during the above period, $8 \mathrm{GW}$ of CCGT have been established. The increase of renewables and CCGT, as well as the economic crisis, lead to an 
important reserve margin in Spain. As a result, CCGT utilization factor decreased from $4.000 \mathrm{hrs}$ in 2006 to 2.000 hrs in 2011, while the share of Coal and CCGT plants decreased from 50\% in 2006 to $30 \%$ in 2011 [16].

Spain has had a capacity payment since the Spanish market was liberalized in 1996. The motivation for generators was the applied price cap and stranded cost compensation. In 2007, the new capacity payments system was introduced at established contracts between TSO and plants selected for reserve purposes with one year duration and remuneration to new investment (capacity payment) for 10 years operation. The remuneration depends on reserve margin requirements estimated by the TSO and it is a capacity charge for new plants, which is a contracted price per MW for each plant [9]. In general, the current legislation sets: i) Incentive payments for new thermal generators which started operating since 2002 and ii) Availability payments differentiated by technology, since 2012 [16].

\subsection{Portugal}

In 2010, Portugal introduced a capacity mechanism that it is based on capacity payments and it is similar to the one introduced in Spain in 2007 [17].

\subsection{Ireland}

Ireland introduced a capacity payment scheme in 2003. The main idea was to ensure the security of electricity supply in view of the expected increase of the electricity demand, taking into account the limitations of the interconnections of the country. According to this scheme, the generators that undertake the construction of new plans receive capacity payments based on their capacity availability [9].

In 2007, the Single Electricity Market (SEM) went live. The SEM is the wholesale electricity market operating in the Republic of Ireland and Northern Ireland. The market operates as a gross mandatory pool market operating with dual currencies and in multiple jurisdictions. The SEM introduced an explicit capacity payment mechanism to encourage provision of adequate capacity. Each year a total capacity payment called the Annual Capacity Payment Sum (ACPS) is calculated by the regulator and it is made available to generators. The total ACPS consists of: i) the annual cost per $\mathrm{kW}$ of a best new entrant peaking generator and ii) a measure of the total $\mathrm{kW}$ of capacity required to meet generation security standard. Remuneration to generators is ca. 75.000-80.000 Euro/MW-year. Nevertheless, there are some concerns over whether the current design has been meeting the objectives efficiently and how robust it will be to change market structures [9].

\subsection{Sweden}

The capacity mechanism in Sweden is based on strategic reserves. The TSO procure capacity contracts through auctions that are open for domestic generation and demand. The Swedish strategic reserve is only for use in extraordinary circumstances during winter months [17]. More specifically, the power plants that are partly or completely dedicated to the strategic reserve are only bid into the Day-Ahead Market (DAM) or the Intra-Day Market (IDM) in curtailment situations, i.e. when the market is unable to equal demand and supply. Then the plants are called to generate by the system operator and they are remunerated through the capacity contracts [9].

\subsection{Finland}

The Finland capacity mechanism is also based on strategic reserves operated by the TSO and it is similar to the Swedish mechanism.

\subsection{The Netherlands}

In July 2014, The Netherlands TSO (TanneN) published an annual report on monitoring the security of supply for the period 2013-2029. According to this, the installed operational production capacity currently totals approx. 28.7 GW. Thermal generation capacity (nuclear, coal-fired, gas-fired and biomass-fired power plants) accounts for approx. $25 \mathrm{GW}$ of this total, while wind and solar energy account for $3.4 \mathrm{GW}$. The Netherlands also has approx $2.7 \mathrm{GW}$ of non-operational or 'mothballed' capacity. Based on this and the estimations for the development of the demand, it is claimed that The Netherlands' domestic electricity production capacity is more than sufficient to meet its domestic demand for the next seven years [18]. Nevertheless, a model for strategic reserves has been prepared but not launched yet [19].

\subsection{Poland}

A major threat for the security of the Polish power system is the viability of the units because of their economic inefficiency of power generation. The increase of renewables in the system requires the redesign of the management of the power system in order to ensure the stability of the system in peak periods. The units that from the economic point of view are "pushed out" by more efficient sources are considered as the next closest production facilities that play this role and it is necessary to support the profitability of the production of these units 
in order to maintain them. According to the current forecasts for the years 2016 - 2018, the Polish power system may experience capacity shortages caused by the decommissioning of old and inefficient power units and the lack of alternative sources, which (despite the fact that they are currently under construction) will not even start operating yet [19].

Currently, the capacity market in Poland is in the design phase. In 2014, work began on the capacity market. Probably, solutions in this area could come into effect in 2016/2017. In parallel, in 2014 implemented bridging instruments are already working, i.e. the cold intervention reserve and the operational capacity reserve. Cold intervention reserve refers to payments to the TSO for keeping units in the ready-to-work mode. The services of the cold intervention reserve can be provided by energy producers whose plans set out the decommissioning by 2017 of the units which are the oldest, and least costeffective (often unprofitable). According to the cold intervention reserve model, producers can keep these units in the reserve in exchange for fixed payments made by the TSO. The estimates of PSE (Polish Transmission System Operator) indicate that the cold intervention reserve should be maintained at around $1.000 \mathrm{MW}$ capacity. The operational capacity reserve means the generating capacities of Power Generating Scheduling Units which are in operation or shut down, representing the excess capacities available to the TSO over and above the electricity demand covered by the Power Purchase Agreement and at the Balancing Market under free generation. Payments for the services of the operating capacity reserve are made based on the reference price of the hourly operational reserve [19].

\subsection{Romania}

In 2007, the Romanian market was fully opened for both electricity and natural gas. On the competition retail market, suppliers sell electricity through bilateral contracts at negotiated prices or through standard offers. Additionally, the new electricity law and national energy strategy have increased market transparency, liquidity and monitoring. Also in 2007, rules for a capacity obligation market were established and in 2008 the Government established the mechanism of direct debit and guarantee for electricity transactions on the day-ahead market [20]. The TSO develops and administrates balancing, ancillary services and cross-border capacity markets. In 2012, bilaterally coordinated auctions for long and short term were organised for cross-border capacity allocation on the borders with Hungary, Bulgaria and Serbia. In July 2013, the Czech Republic, Slovakia, Hungary, Romania and Poland signed a Memorandum of Understanding to extend the existing market coupling in Central Eastern Europe by including Romania and Poland [21].

\subsection{Germany}

The German electricity market is undergoing a period of drastic changes (Energiewende). The role of renewable energy will continue to increase in the power supply market, while the use of nuclear energy will phase out by 2022. As a result, a $12 \mathrm{GW}$ of generation capacity will be shut down. The role of the electricity market should be to maintain the balance between power generation and consumption, especially in view of the fact that the shares of wind and solar energy in the power supply mix increase. To achieve this, it has to fulfil two tasks: Firstly, it must ensure that sufficient capacity is available (i.e. reserve function) and secondly, that this capacity is used at the right time and to the extent necessary (i.e. dispatch function). In October 2014, the Federal Ministry for Economic Affairs and Energy of Germany published a Discussion Paper, called Green Paper [22] that focuses on how to develop a future market design and regulatory framework for the electricity sector to ensure that the power supply is secure, cost-efficient and environmentally friendly.

According to the Green Paper, two basic approaches could be considered for the long-term development of the electricity market. The first is to optimise the electricity market with a credible legal framework that investors can rely on and which allows electricity consumers to independently determine through their demand how much capacity is maintained. The second is to set up a further market alongside the electricity market for the maintaining of reserve capacity. It is also claimed in the document that international experience shows that the creation of capacity markets takes several years from the fundamental decision until the time that they become fully operational. It is therefore necessary in any case to build a safeguard into the system in the form of reserve capacity for the transition phase.

\subsection{UK}

The UK is the first country in the EU that started a capacity auctions market. The first auction for the capacity of 2018/2019 performed in December 2014. The idea was to ensure that there will be enough generators connected to the power network to meet peak (winter) demand, even when intermittent renewables are generating less electricity. Additionally, a key intention of 
the auction was to encourage new build generation [23]. The results of the first capacity market auction were released in December [24]. According to the forecasted maximum demand for 2018/2019, the government wanted commitments from 48,6 GW. The auction resulted in a price of $£ 19,4 / \mathrm{kW}$ of power capacity and the total cost of the contracts will be about $£ 931$ million [25]. The winners of the auction will sign contracts to provide specific amount of power at 4 hours' notice (for at least 4 hours) to the national transmission system operator [23].

Most of the power plants, 43,7 GW of the 48,6 GW, already exists and has been signed up under one-year contracts, meaning they may re-enter next year's the auction. So, most of the generating capacity has been only secured for the first year that the scheme comes into force. A further 3,1 GW of existing capacity was contracted under 3 year contracts. Nevertheless, 59 new power plants totalling only $2,4 \mathrm{GW}$ of capacity were offered 15 year contracts. It is important to notice that only 5,3\% (77 units) of projects included in capacity market are new builds. The reason why the auction attracted only small amounts of new build is assumed to be the final price $(£ 19,4 / \mathrm{kW})$ that is considered as low [23]. The auction's biggest winner was gas power, with $22.3 \mathrm{GW}(45,2 \%)$ of new and existing gas power plants receiving contracts [25].

Table 1, illustrates some of the existing (at that time) capacity mechanisms in different EU countries and provides the assessment of their cost and remuneration levels [26].

Table 1 Annual cost of existing mechanisms in European countries, 2013

\begin{tabular}{|c|c|c|c|c|c|}
\hline & $\begin{array}{l}\text { Marke } \\
\mathrm{t} \\
\text { design }\end{array}$ & \multicolumn{3}{|c|}{$\begin{array}{l}\text { Annual cost of capacity } \\
\text { remuneration }\end{array}$} & $\begin{array}{l}\text { Committed } \\
\text { capacity } \\
\text { MW }\end{array}$ \\
\hline & & (1) & $(2)$ & (3) & \\
\hline Greece & $\mathrm{CP}^{*}$ & 451 & 9,18 & 41.030 & 11.008 \\
\hline Ireland & $\mathrm{CP}$ & 529 & 14,9 & 78.000 & 6.778 \\
\hline Italy & $\mathrm{CP}$ & $100-160$ & 0,5 & - & - \\
\hline Spain & $\mathrm{CP}$ & 758 & 2,7 & 30.506 & 24.847 \\
\hline Sweden & $\mathrm{SR}^{* *}$ & 12 & 0,1 & 6.981 & 1.726 \\
\hline Finland & SR & 19 & 0,3 & 31.216 & 600 \\
\hline Norway & SR & 25 & 0,2 & 82.753 & 300 \\
\hline PJM & $\mathrm{CP}$ & 4.275 & 5,5 & 31.401 & 136.144 \\
\hline $\begin{array}{l}\text { (1) } \\
\text { (2) } \\
\text { (3) }\end{array}$ & $\begin{array}{r}\text { pacity p } \\
\text { trategic } \\
\text { Tot } \\
\text { Per } \\
\text { Per }\end{array}$ & $\begin{array}{l}\text { cost Mill. EL } \\
\text { oss electrici } \\
\text { mmitted cap }\end{array}$ & $\begin{array}{l}\rho \\
\text { gen. EL } \\
\text { ity EUI }\end{array}$ & $\begin{array}{l}O / M W h \\
\text { /MW/yea }\end{array}$ & \\
\hline
\end{tabular}

\section{Conclusions-future work}

A number of European countries have already implemented capacity markets and some other are planning to do so in the near future. Political and regulatory reluctance for (very high) prices during scarcity times along with the increasing penetration of renewables pose a serious challenge on the ability of energy-only markets to safeguard adequate dispatchable generation capacity to cover both peak demand and ramping requirements for balancing the intermittent renewables. European institutions, with European Commission as frontrunner, work to set an efficient framework for the European capacity markets so that their emergence will not hinder the completion of the single European electricity market. Security of supply (SoS) is considered as one of the main pylons of the new EU's Energy Union strategy but its safeguarding should be achieved in an optimal way, also regarding cost for the consumers. As far as SoS in electricity is concerned, regional cooperation and capacity auctions could be the long-term optimal answer to that question.

The present paper provides a comprehensive review of the historic development and the current situation in Europe regarding the emerging capacity markets. Future work in that field will focus on economic/econometric analysis of different type of capacity markets as these markets will become already in the near future a standard part of the European electricity markets' design.

\section{References}

[1] Sweppe, F.C., Caramanis, M.C., Tabors, R.D. and R.E. Bohn. "Spot pricing of electricity", Boston, Kluwer Academic Publishers. 1988.

[2] Joskow, P. "Capacity payments in imperfect electricity markets: need and design". Utilities Police, 16:159-170. 2008.

[3] EC. "Guidelines on State aid for environmental protection and energy 2014-2020", Official Journal of the EU. 2014/C 200/01. 2014.

[4] ACER. "Energy Regulation: A Bridge to 2025, Conclusions Paper”, 19 September 2014.

[5] ENTSO-E. "Market design policy paper", September 2014.

[6] ENTSO-E. "Cross-border participation to capacity mechanisms", February 2015.

[7] Eurelectric. "A reference model for European capacity markets", March 2015. 


$$
\begin{array}{r}
\text { G. Stamtsis, V. Lychnaras } \\
\text { Integration of capacity markets into the European electricity market }
\end{array}
$$

[8] Intergovernmental. "Joint declaration for regional cooperation on security of electricity supply in the framework of the internal energy market”. 2015. URL:

http://www.bmwi.de/BMWi/Redaktion/PDF/J-

L/joint-declaration-for-regional-cooperation-onsecurity-of-electricity-supply-in-the-framework-ofthe-internal-energy-

market,property $=$ pdf, bereich=bmwi2012, sprache $=$ en , rwb=true.pdf

[9] EC. "Capacity mechanisms in individual markets within the IEM", DG ENER - Directorate B, June 2013.

[10] RTE. "French capacity market: Report accompanying the draft rules", Réseau de transport d' électricité (RTE), 9 April 2014.

[11] De Geyter, A. "The Belgian Electricity market: overview, analysis of today's issues and suggestions to fix it", Energy Outlook, Sia Partners, 20 August 2013. URL: http://energy.siapartners.com/20130820/the-belgian-electricitymarket-overview-analysis-of-todays-issues-andsuggestions-to-fix-it/

[12] Gonne, R. and W. Vandenberghe. "Capacity market in Belgium", FSR workshop, Florence, 11 October 2013.

[13] PancoSalvi, U., De Cola, G., Heinlein, B. C. and S. Knepper. "Capacity payment in Italy and the German case", Client Briefing, Clifford Chance, 24 April 2015.

[14] SQ Consult. "Capacity Remuneration Markets in Europe", Newsletter, The Netherlands, September 2013.

URL: http://www.sqconsult.com/content/newsletter_html/s qconsult_mailing 04-09-2013.html

[15] Patrian, R. "Italy gears up for 2017 electricity capacity market launch", 12 March 2015. URL: http://www.icis.com/resources/news/2013/09/11/970 5136/first-italian-electricity-capacity-auction-to-beannounced-this-year/

[16] San Román, T. G. "Capacity markets design with a growing RES penetration", 1st OMIE International Workshop, Madrid, 3 July 2012.

[17] NEPP. "Capacity mechanisms: Revived interest in capacity mechanisms throughout Europe in the face of high volumes of intermittent generation", NEPP Synthesis results, September 2011.
[18] TenneT, "Report on monitoring of security of supply 2013-2029”, TenneT TSO B.V., July, 2014. URL:

http://www.tennet.eu/nl/news/article/electricitysupply-in-the-netherlands-sufficient-for-foreseeablefuture.html

[19] Łuba, P. and K. Rajczyk. "5 Myths of the Polish Power Industry 2014", 4th edition of PwC and ING Bank report, May 2014. URL: http://www.pwc.pl/en/publikacje/2014/5-mitowpolskiej-energetyki.jhtml

[20] EBRD. "Romania country profile", European Bank for Reconstruction and Development. 2014. URL: http://www.ebrd.com/downloads/legal/irc/countries/ romania.pdf

[21] EC. "Country reports - Romania", European Commission - Energy. 2014. URL: https://ec.europa.eu/energy/en/content/2014countryr eportsromania

[22] Federal Ministry for Economic Affairs and Energy (BMWi). “An Electricity Market for Germany's Energy Transition: Discussion Paper of the Federal Ministry for Economic Affairs and Energy (Green Paper)", Berlin, October 2014. URL: http://www.bmwi.de/EN/Topics/Energy/ElectricityMarket-of-the-Future/green-paper.html

[23] Parr, M. "UK "capacity market" is not a market it’s state aid ( $£ 1$ billion/year)", energypost, 26 January 2015. URL: http://www.energypost.eu/ukcapacity-market-market-state-aid-1-billionyear/

[24] National Grid. "Provisional Auction Results: T-4 Capacity Market Auction 2014”. URL: https://www.gov.uk/government/uploads/system/upl oads/attachment_data/file/389832/Provisional_Resul ts_Report-Ammendment.pdf

[25] Hope, M. "Capacity market secures some new gas while providing stay of execution to old coal", The Carbon Brief, 19 December 2014. URL: http://www.carbonbrief.org/blog/2014/12/capacitymarket-secures-some-new-gas-while-providingstay-of-execution-to-old-coal-\%281\%29/

[26] EC. "Commission staff working document: Generation adequacy in the internal electricity market-guidance on public interventions", SWD (2013) 438 final. 2013. 